\title{
An Overview of Syntactic Tense \& Aspect: From both Grammatical \& Lexical Perspectives
}

\author{
Kamal Kahzal \\ Department of the English Language, Imam AL- Kadhum College (IKC), Iraq
}

\begin{abstract}
Language can be complicated even within one language, such as in English. Rules of grammar, construction, and syntax are used to express ideas clearly so that others understand the intention behind them. However, these rules can lead to challenges in ensuring that ideas are effectively communicated and interpreted, particularly because word choice in the context of grammar and syntax rules can impact the way an expression is interpreted. This can be illustrated through an examination of the perfective aspect of syntax. The purpose of this research is to provide an overview of aspect and tense from both the grammatical and lexical perspectives.
\end{abstract}

Index Terms - perfective, imperfective, lexical, grammar, tense, aspect

\section{INTRODUCTION}

Language can be complicated even within one language, such as in English. The way individuals put words together and express ideas are intended to help the hearer or reader to understand the meaning behind what is said. According to DeLancey (2001), "Put in phenomenological terms, the fundamental communicative function of language is to provide the speaker with tools with which to guide a hearer in constructing an experiential representation" (p. 371). Rules of grammar, construction, and syntax are used to express ideas clearly so that others understand the intention behind them. However, these rules can lead to challenges in ensuring that ideas are effectively communicated and interpreted, particularly because word choice in the context of grammar and syntax rules can impact the way an expression is interpreted. According to Pustejovsky (1991), "It is my opinion that the representation of the context of an utterance should be viewed as involving many different generative factors that account for the way that language users create and manipulate the context under constraints, in order to be understood" (p. 411). That is, the way an idea is constructed and expressed determines how an individual understands what is expressed and what it means (Bardovi-Harlig, 1992).

In addition, some components of grammar, such as aspect, can allow for multiple interpretations, which must be considered when constructing expressions. Understanding the intricacies of language can help individuals express themselves more effectively as well as help individuals learn new languages, particularly when they have syntactic similarities to their native languages. As a result, individuals are able to gain a deeper understanding of language, its use, and its importance in conveying ideas.

This can be illustrated through an examination of the perfective aspect of syntax. The perfective aspect is an aspect, or viewpoint, within language that helps to convey the temporal elements of an expression. Typically, aspect and tense work together to give clues as to the timeframe of an expression. The perfective aspect is one element of aspect. While it is separate from tense, as in perfect tense, the two are closely related and frequently researched together. The purpose of this research is to examine the perfective aspect of linguistics, how it is used, and its importance in language. This research explores aspect and tense from the perspective of grammatical aspect and tense and lexical aspect, with particular attention to the perfective and imperfective in the grammatical context and the four classifications of lexical aspect.

\section{ASPECT AND TENSE}

Aspect and tense refer to the temporal clues that are used in language for greater understanding of the intention behind what is said or written (Hamm \& Bott, 2014). These temporal clues are also valuable so that language adheres to rules of grammar and syntax, which furthers an understanding about what is said and meant. For those who speak or understand a language, these clues can be obvious, particularly in the context of tense. For example, since the past tense of run is ran in English, it is easy to determine whether the use of the word is in past tense. Other uses, particularly in other languages, are more difficult to identify, and require the use of additional clues and rules to determine the temporal intention of the utterance.

Since the concepts of tense and aspect are closely related, and frequently work together in grammar to create an understanding of the utterance and its context in time. However, they are separate ideas in grammar and serve different purposes within language and syntax. Understanding the two components individually can help create an understanding as to how they work together. This can then build a foundation on which the meaning of utterances can be better 
identified and understood as well as used properly, particularly for language learners (Robinson, 1990). This research provides a foundation of knowledge about tense and aspect in order to understand the perfective aspect more effectively.

\section{TENSE}

For many, tense is the easiest concept to understand because of the way words and phrases are changed to denote tense. Within the context of grammar and linguistics, there are three tenses: past, present, and future. For example:

(1) (a) Emily sat in the chair.

(b) Emily is sitting in the chair.

(c) Emily will sit in the chair.

In each of these examples, Emily sits in the chair. However, the tense of the sentences provides a different perspective for when that will happen. The grammatical tense lets the reader or listener know when the event or state occurred to provide context and understanding.

In (1) (a), Emily sat in the chair in the past as sat is the past-tense form of sit. Therefore, sentence is written in past tense. Using the knowledge of the past-tense form of the verb sit, the verb is the temporal clue for the sentence. Since the verb is the form that designates the sitting took place previously, the reader or listener knows that the event expressed already occurred. Therefore, it is in past tense. Smith assumes that "the syntax of a fully-tensed language includes a tense phrase (TP)." Every sentence has direct information about temporal location; (i) the default interpretation of present tense sentences as located in the present, (ii) past tense conveys that the reference Time precedes the Speech Time. The other types of languages have a syntactic aspect phrase but no TP, Gueron, J. and Lecarme J. (2008). In these languages temporal location in inferred from aspectual information.

In (1) (b), Emily is sitting in the chair currently. In this sentence, is sitting is the present-tense form of sit, with the linking verb is serves as a link between the subject (Emily) and information about the subject (sitting in the chair). Present tense frequently uses linking verbs, particularly in English, to connect the subject and the action. This method of construction is often found when the information about the subject is a state of being rather than an explicit action, such as in sitting. Sitting is not really an action, but when an individual is sitting, the verb sit is a state of being for that subject. Therefore, the linking verb $i$ s connects the subject to that state of being.

In (1) (c), the sitting takes place in the future. The compound verb will sit denotes that the sitting has not yet taken place, but is going to. In this example, will is a modal verb, and its function in the sentence is to convey functional meaning. As in the case of (1) (b), the use of the word sit suggests a state of being rather than an action. Therefore, the verb will helps connect the subject (Emily) to the state of being (sit). However, (1) (c) is different in that is (in (1) (b) is a linking verb rather than a modal verb. In (1) (c), sit is still the main verb, with the modal verb will conveying information about the main verb. In (1) (b), on the other hand, the linking verb (is) is the main verb with sitting as the state of being.

Another component to tense is perfect or imperfect tense. In imperfect tense, the action expressed occurred in the past and do not occur in the present. For example:

(2) (a) Emily sat in the chair an hour ago.

Typically, imperfect tense will need some indicator that the action is not only complete, but that it is not occurring at the time of utterance. In (2) (b), the past tense of sit indicates that it occurred in the past, suggesting completion. However, if the sentence were complete with only the past-tense verb (Emily sat in the chair.) there would be no indication as to whether she were currently sitting in the chair or if she were no longer sitting in the chair. As a result, this would not give enough clues on the surface to suggest imperfect tense. The addition of an hour ago lets the listener or reader know that the event occurred in the past and that she is not sitting in the chair currently. This makes the action imperfect rather than perfect.

Perfect tense, on the other hand, occurs when the verb expressed occurred in the past. That is, the action is not only complete, but it will not occur again or is no occurring currently. This differentiates verb usage from events that occurred in the past, but are either also currently occurring, or may occur again in the future. Despite the emphasis on the past, perfect tense is not limited to the past. Perfect tense may be used in past, present, and future tense. What makes the tense perfect is the form of the verb and other temporal clues to suggest that the event occurred in the past and is not currently occurring.

While past perfect tense is straightforward, using past-tense verbs to express the idea or event, future and present are a little different. Perfect future tense expresses an event that will be complete at a given time in the future. For example:

(2) (b) Emily will have sat in the chair by the time her lunch break is over.

In this example, the event has not occurred at the time of utterance (future tense), but by a given time (by the time her lunch break is over), the action will be complete (will have sat). In this way, the sentence is both perfect (complete action rather than ongoing) and future (has not occurred at the time of utterance). All of the clues, when taken together, show the completion of the action as well as the future tense of the verb, making the example future perfect tense.

In perfect present tense, a form of the verb have is used with a past participle. Perfect present will be used throughout this research as a basis of understanding perfective aspect. Therefore, a stronger background in perfect present tense is valuable for this discussion. For example:

(3) (a) Emily has sat in the chair. 
In this example, the verb sat is in the past tense, but the verb has shifts the sentence to perfect present tense rather than remaining in past tense. Perfect present is a compound tense. Therefore, it requires both the main verb (sat) and the auxiliary verb ( has). These two verbs must work in cooperation to create the perfect present tense.

Remember that perfect tense requires that the action is complete. Present tense suggests that an action is current or immediate. By combining the past tense of the verb (such as sat) with the present tense of the auxiliary verb (has), the sentence is able to meet both of these grammatical requirements. In the use of a stative verb, this method can also be used. A stative verb is one that is ongoing or continuous, such as wanted (Binnick, 1991). These verbs are often used to express a state of being or state of mind, such as in the case of emotions. While some stative verbs may be more complex to use in the perfect present, they can be used since even stative verbs can be presented in the past tense (suggesting completion). For example:

(3) (b) Emily has wanted her chair.

It should be noted that, in the case of some verbs, additional temporal clues must be included to provide enough context for the perfect present tense. This helps reinforce the present tense as well as the idea of completion, referred to as telicity.

The usage of perfect present tense can be found in languages other than English, as well (Smith, 1997). Examining the usage in other languages is beneficial when translated accurately. In English, many of these translations are not grammatically correct, but the errors emphasize the perfect present tense usage. For example:

(3) (c) Ivan šte e pristignal v Sofia do dovečera.

This sentence, which is Bulgarian, translates to "Ivan will be arrived in Sofia by tonight." In this sentence, be arrived is used in the same way as have arrived in English. In addition:

(3) (d) Cuma gibi Istanbula var-mis-ti-m.

This sentence, which is in Turkish, translates to "I had arrived in Instabul by Friday." Once again, the sentence uses a form of have and a past participle to create perfect present. This approach combines the use of past and future tense as a way to understand the present.

\section{ASPECT}

Aspect is different from tense, focusing more on the "notion" of time rather than clear, temporal clues like past, present, and future. According to Duan (2013), "Aspect was originally put forward as a category in general linguistics, but not specific to any particular language. Aspect, as a grammatical category in general linguistics, is indicated mainly by changes of verb forms" (p. 265). While aspect also deals with temporal clues, aspect may include elements from outside of the event or state in the sentence to suggest additional components or a part of an event still in progress. Singh (1998) explains, "Aspect refers to the way an event is viewed internally. [...] Sometimes, aspect is referred to as situation internal time, as in Smith" (p. 171). Rather than strictly temporal, aspect provides a viewpoint of the language. For example:

(4) (a) Emily sat in the chair.

(b) Emily was sitting in the chair.

In (4) (a), the sentence presents a complete event. Emily sat in the chair. That is all there is to the sentence. However, in (4) (b), there is an implication that sitting in the chair is only a component to a greater event or state, or one that is in progress but not complete. For example, Emily was sitting in the chair [when the lights went out]. The event, relative to (4) (b), is incomplete. The temporal clues suggest there may be more to the event than Emily simply sitting in the chair.

The elements of this event beyond sitting in the chair are not apparent from the sentence on its own. In this situation, a reader may rely on additional sentences or context clues from additional sentences to complete the event. Aspect and tense, though they are different, are closely related, and impact each other in linguistics. According to Bybee and Dahl (1989):

Theoretically, a combination of three tenses (present, past, and future) and two aspects (perfective and imperfective) would yield at least six combinations. This possibility, however, is practically never realized in a single language. In fact, it seldom happens that more than four combinations are distinguished, due to a universal tendency for there to be a coupling between perfectivity and the past, in most cases resulting in a system where a gram with the meaning 'perfective past' is opposed to everything else [...]. (p. 83)

Russian and Bulgarian which belong to the Slavic languages have rich forms to As can be understood from Bybee and Dahl (1989), aspect can become complicated when it is examined in other languages, due in large part to the way other languages change their verb forms.

This can be understood through an understanding of how linguistics occur in various languages. For example, according to Duan (2013):

Some inflected languages like show aspect. English is between an analytical language and an inflectional language. Without special form to show aspect, English resorts to inflectional changes of adding auxiliary verbs to verbs to indicate aspect. Chinese is a language without inflectional changes, so aspect is revealed by semi-dependent function words. (p. 263)

In other words, it is because of English as an analytical language that the perfective aspect does not really exist. 
The same is true in Chinese, in which the lack of inflectional changes results in aspect being conveyed through semidependent function words. For example, Soh and Gao (2006) argue that the particle -le in Mandarin Chinese functions as a marker for the perfective aspect within the language (Li, Thompson, \& McMillan Thompson, 1982). According to Li, Thompson, and McMillan Thompson (1982):

The basic communicative function of $l e$ is to signal a 'Currently Relevant State (=CRS). That is, le claims that a state of affairs has special current relevance to some particular Reference Time. The Mandarin le, then, can be easily seen as an exponent of the perfect aspect, the basic discourse function of the Perfect being, as we have said, to relate some state of affairs to the "current" time, i.e., in the unmarked case, the conversational setting in which the speaker and hearer are participating as interlocutors. (p. 22)

This is the opposite of the use of -ing in English, which serves as a marker for the imperfective aspect. The imperfective is present when the event expressed is incomplete. In English, the use of -ing suggests currency, as with the Mandarin -le, but in English, -ing suggests that the verb is currently occurring rather than having been completed.

The use of textual markers in this way takes the place of inflectional changes when they are absent in a given language. In addition, despite similarities between languages, differences in syntax and grammar can result in insurmountable differences, leading to the need for interpretation when translating. This can be illustrated in Figure 1 below.

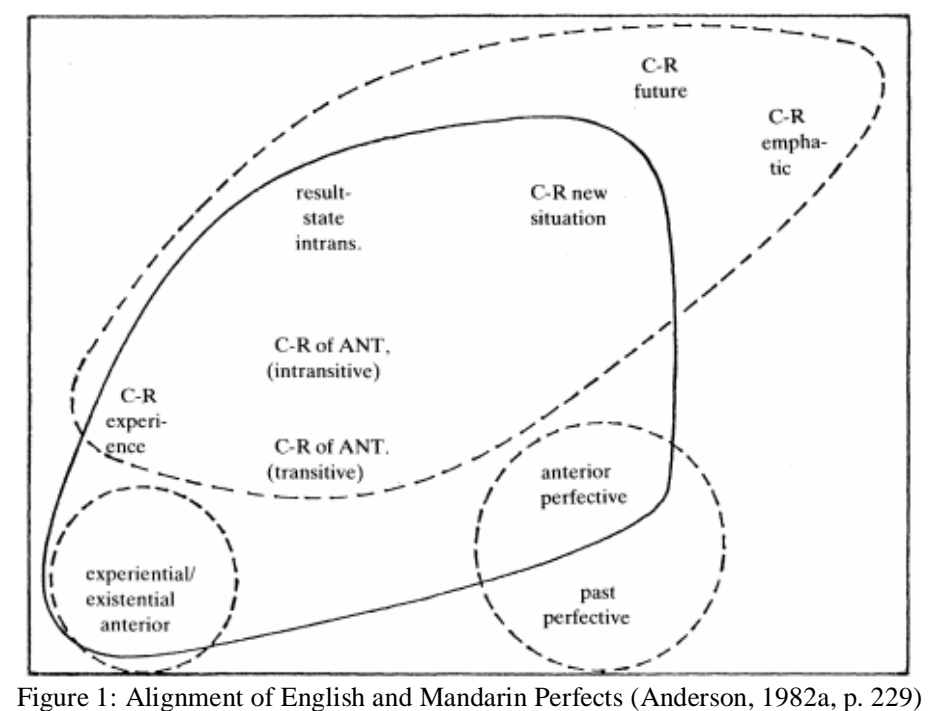

This figure represents the uses of the perfect in use in English and Mandarin. Mapping the alignment shows that, in most cases, categories of words have single uses (Anderson, 1982a). Anderson (1982a) illustrates this through a comparison of Mandarin and English. According to Anderson (1982a, p. 228):

The English Perfect has a range of uses, as has long been recognized (see extensive bibliography in McCoard 1978). Major ones are in (1).
(1) (a) "experiential":
(b) "current relevance of anterior":
(c) "new situation":
(d) "result-state":
(e) "continuous":
Have you (ever) been to Japan?
(f) "anterior": $\quad$ John thought Mary had left. / Mary will have left by then.
(in the analysis here called 'anterior continuing')
He has studied the whole book. (so he can help)
("hot news") Io has just erupted! (discovery of volcanos on one of Jupiter's moons)
He has gone. (or) He is gone. (is not here)
I have been standing here for three hours. (still here)

Anderson (1982a) concludes that these meanings are similar to each other in some way, which places them near each other on a grammatical map. Therefore, in Figure 1, the relationship between the classifications can be visualized and, thus, understood. Despite the similarities, problems arise when different languages attempt to satisfy multiple categorical requirements in a map that does not entirely overlap, as in the case of Mandarin and English (Anderson, 1982a). In Figure 1, the solid line represents the English category boundary, while the dashed line represents the Mandarin category boundary. As can be seen, there are areas that do not align, such as in past perfective.

\section{GRAmMatical ASPECT}


Grammatical aspect refers to the grammatical construction of words that denotes aspect. The two categories of grammatical aspect and tense examined for the purposes of this research are perfective and imperfective. The temporal view of a state or event in the perfective aspect occurs as a whole regardless of the internal structure of the utterance. In the imperfective aspect, aspect is expressed relative to the internal structure of the utterance rather than as a whole.

For those who are unfamiliar with grammar analysis and those who may be learning a language for the first time, this may be a difficult concept to grasp. The most effective way to identify and differentiate between the two is through an example. Mourelatos (1978) uses the quoted example: "'A man may be walking to the Rose and Crown, and yet never walk there, perhaps because he is run over on the way" (p. 420). This sentence includes both the perfective and the imperfective, making it an effective example to use for identification and analysis of both of these grammatical constructs. According to Mourelatos (1978):

In Kenny's example of the walk to the Rose and Crown, the first occurrence of the verb is in imperfective, the second in perfective aspect. The contrast is easily missed in English because the suffix "-ing" is not only part of the marker of the imperfective aspect but often simply a neutral participial or gerundial ending. (p. 421)

Mourelatos (1978) explains that the example has two options: perfective or imperfective aspect throughout.

However, in order for either of those options to be utilized, the sentence would have to be rewritten. To apply perfective aspect throughout, the sentence would read, "If it is now true that he has this very moment walked to the Rose and Crown, it will be true in the future that he did walk, or had walked, to the Rose and Crown" (Mourelatos, 1978, p. 421). To apply imperfective aspect throughout, the sentence would read, "If it is true now that he is walking, or has been walking, to the Rose and Crown, it will be true in the future that he was walking, or had been walking, to the Rose and Crown" (Mourelatos, 1978, p. 421). However, these grammatically correct rewritings may be much more difficult to understand.

Mourelatos (1978) further states that, in English, the difference between the perfective and imperfective aspects may be overlooked in English because of the use of the -ing ending to walk in the first verb. In English, -ing is a marker for the imperfective aspect. As a result, when it is seen, the reader or listener expects an imperfective aspect rather than a perfective aspect. With what is known about the perfective aspect, it would be expected that the first part of the sentence would read, A man may have walked to the Rose and Crown, which includes the form of have and a past participle. However, this is a complexity added to the analysis of the example by virtue of the English language usage of -ing. In this instance, an individual must have a strong understanding of the intricacies of language and grammar in order to identify the perfective aspect in the example.

This is only one example of the complexities of perfective versus imperfective aspects. According to Shirai (1998), "[...A]lthough the distinction between perfective and imperfective is the most fundamental of aspectual distinctions, analysis of [Japanese, Chinese, Korean and English] reveals that this distinction can sometimes be murky" (p. 661). In these languages, there are strong similarities between the two aspects, which can make it difficult to draw clear distinctions between them, and can then make it difficult to identify them and use them properly. This is particularly true for those learning one of these languages and whose native language does not have the same similarities. This section explores the grammatical perspective of aspect and tense in linguistics in order to understand them better and be able to distinguish between them.

Perfective. Perfective aspect provides a temporal view of a state or event as a simple whole regardless of the internal structure (Smith, 1997). Most often, in English, this is expressed using a simple past-tense verb. For example:

a. Emily sat in the chair.

In the perfective aspect, there is a clear beginning and end to whatever event or situation being expressed in the sentence. It is important to note that, in the example (5) (c), the verb sat is not a stative verb, but a dynamic one. Therefore, the emphasis is on the action of sitting rather than on sitting as a state of being. This sentence is a simple whole and took place in the past, therefore, it employs the perfective aspect.

In returning to the discussion of the perfective aspect, at the time of utterance, the event is complete, which means it took place in the past. This distinction is important in the perfective aspect because it is a primary characteristic of the aspect. According to Smith (1997):

The perfective span is realized according to the endpoint properties of the situation type. The initial endpoints of all situations are natural. The final endpoints of Activities are arbitrary; those of Accomplishments are natural; Semelfactives and Achievements have only a single point because they are one-stage events. Results obtain only for telic events. The temporal schema of States does not include endpoints; and Stative sentences in the English perfective do not include their endpoints. (p. 128)

Smith (1997) explains that the endpoint properties of the event or situation are key to the perfective aspect. Part of the reason for this is in the classifications. The type of classification is dependent on the duration, which is the span of time in which the verb occurs, of the verb. Each classification has its own durative characteristics that must be considered. If the perfective aspect did not include the endpoint, the verbs would not be able to categorized according to the classifications identified by Smith (1997). Four of these classifications - Accomplishment; Achievement; State; and Activity - are discussed in greater depth in the next section.

Higginbotham James (2009) detected that "English perfective is purely aspectual, serving to shift from a predicate of events $e$ to a predicates of events $e^{\prime}$ that is the result of $e$. the head Perf has, therefore, two 
argument positions and expresses the relation $\mathrm{R}\left(\mathrm{e}, e^{`}\right)$ satisfied by an ordered pair of events such that $e^{`}$ is a result of $e$. because by assumption, results temporally follow the states, it follows that the situations characterized by a predicate $\mathrm{F}(e)$ are Past with respect to a present result $e `$ of $e$ Gueron, J. and Lecarme, J. (2008). According to this analysis, the Perfect is not associated with Tense at all except derivatively."

Imperfective. Imperfective aspect expresses a state or event relative to the internal structure rather than as a whole. According to Smith (1997), "Imperfective viewpoints present an interval without endpoints. They can in principle focus either preliminary, internal, or resultant, stages of situations" (p. 130). For example:

(5) a. Emily was sitting in the chair.

In the imperfective aspect, it is clear that the process, event, or state is not completed. Therefore, the interpretation is that it is continuing at the time of utterance.

The three most common types of imperfective viewpoints are general, progressive, and resultative (Smith, 1997). According to Smith (1997), "The English imperfective, a progressive, is available for the event types that have intervals associated with them; it has the stage property that is associated with the dynamism of events" (p. 130). Generally, the imperfective can be applied in any situation. Since the imperfective viewpoint presents part of a situation, it is inherently progressive; there is no fixed, natural, or designated endpoint, which makes the event ongoing (progressive).

The imperfective can also be used in any tense: present, future, or past. It is the construction of the verbs and verb phrases that denote the tense in the imperfective. In English, the progressive is used to designate ongoing events such as:

(6) (b) Emily is sitting in the chair.

In this example, Emily is (currently) sitting in the chair. Since there is no designation of an endpoint or a timeframe, this is an ongoing event, making it imperfective.

Another component of the imperfective is the habitual, in which events are repeated or occur periodically. Typically, these situations or events do not have their own verb forms. Therefore, sentence construction relies on specific compound verbs to convey the habitual nature of what has occurred. For example:

(6) (c) Emily used to sit in the chair.

In this example, it is suggested that sitting in the chair is not only in the past, but there is no sense of an endpoint within the sentence other than it occurring in the past. Therefore, this conveys the past imperfective. In English, which does not have a general imperfective, the simple past tense is frequently used with additional elements to convey the continuous or ongoing nature of the event. For example:

(6) (d) Emily sat in the chair continuously through the night.

In (6)(d), the verb is simplified: sat. However, the addition of the phrase continuously through the night is a temporal clue that conveys the ongoing nature of the past event.

A further complication in English is the inability to use progressive stative verbs in the imperfective (Dowty, 1977). For example:

(6) (e) Emily was wanting the chair.

is grammatically incorrect. Instead, the sentence should read:

(6) (f) Emily wanted the chair.

Conversely, other languages include imperfect, stative verbs. Quite often, these verbs appear in the progressive naturally in these languages. For example, according to Garey (1957):

The present indicative is imperfective [in French] except when the verb designates the very act of making the affirmation in which it figures, as in je vous dis que oui, je demande une explication de votre conduite, j'affirme que tout ce que j'ai dit est vrai. In these sentences the present is perfective. Of the imperfective uses of the present, some are simply imperfective, others are iterative; thus, vous buvez trop can mean 'you drink too much' or 'you are drinking too much'. Unlike English, French does not mark this difference formally. (p. 110)

In English, the construction of drinking too much is based on the duration of the drinking as well as whether or not an endpoint is indicated. However, in French, the idea is constructed using the same words regardless of the intention. As evidenced from the differences in conveying a single idea (particularly in the imperfective) in French and English, syntax and grammar construction vary based on language. Regardless of the language, understanding the rules of construction, such as in an understanding of the perfective versus the imperfective, can not only help with the usage of a native language, but can help individuals more effectively learn a new language, as well.

It should be noted that this problem (in English) does not occur in action verbs but is limited to stative verbs. For example:

(6) (g) Emily was sitting in the chair.

In (6) (g), which is the same construction as (6) (a), the pairing of the progressive action verb sitting with a form of to be (was), shows that the sitting was continuous or ongoing.

\section{LEXICAL ASPECT}

The second perspective of aspect to discuss in this research is the lexical aspect. The lexical aspect focuses on the lexicon, which is from where items are drawn for syntax (Marantz, 1997). According to Marantz (1997): 
The leading idea of Lexicalism might be summarized as follows: Everyone agrees that there has to be a list of sound/meaning connections for the atomic building blocks of language (=the "morphemes"). There also has to be a list of idiosyncratic properties associated with the building blocks. (p. 201).

The connection between these components is illustrated in Figure 2 below. Syntax combines sound and meaning, and syntax is drawn from the lexicon. Sound and meaning work together to contribute to syntax (and lexical combining).

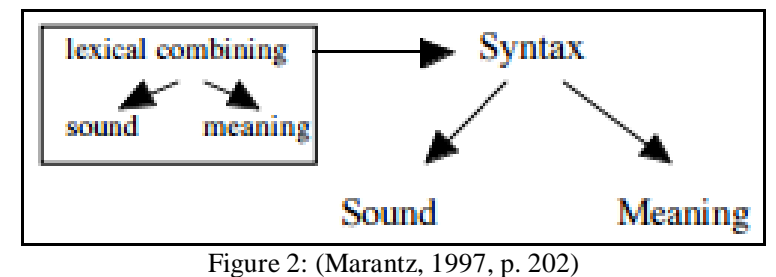

Within the context of this research, lexical aspect is the aspect of language as it relates to lexicalism. Though it is a perspective of aspect, lexical aspect can be viewed as slightly different from aspect in that it is understood through aktionsart, which is a German term used to describe aspects that do not have textual markers to denote them, such as through a lack of inflection (Bache, 1982). As suggested by the name, aktionsart focuses on action. Specifically, it refers to the circumstance of action. The circumstance of action provides context for understanding what is expressed just as other concepts of aspect do.

Lexical aspect is classified in four categories: accomplishment, achievement, state, and activities (Hamm \& Bott, 2014). However, some researchers also include semelfactives, which are not addressed in this research. In addition, some scholars have developed alternative interpretations of these four categories. For example, Mourelatos (1978) explains the Kenny-Vendler typology, which consists of three categories - situations, occurrences, and events - each with binary contrasts. This is illustrated in Figure 3 below.

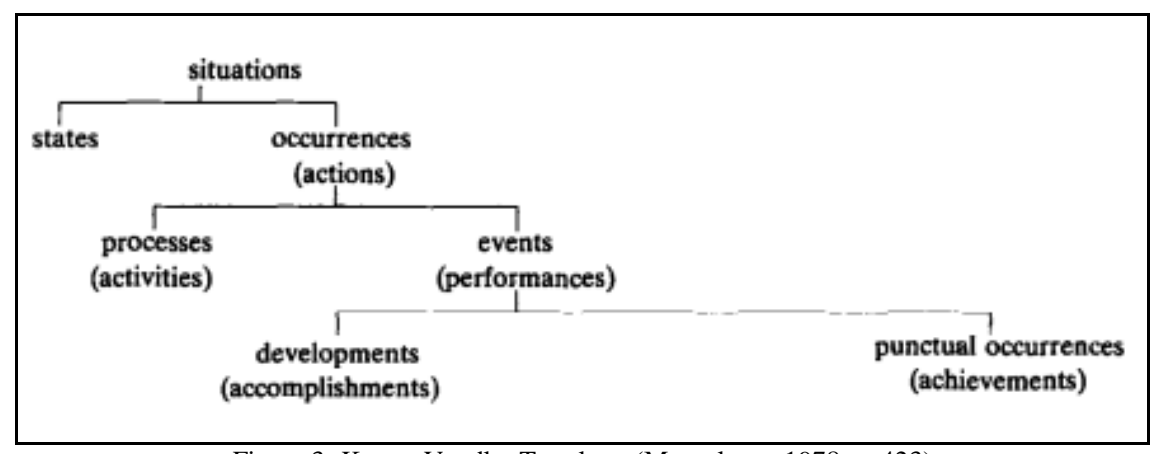

Figure 3: Kenny-Vendler Typology (Mourelatos, 1978, p. 423)

In this typology, the original four classifications - actions, activities, accomplishments, and states - can be found. However, the similarities between achievements and accomplishments are recognized, as they are both nested beneath events (performances) in the Kenny-Vendler typology model. This section explores the lexical perspective of aspect through an explanation of accomplishment, achievement, state, and activities. These four classifications are rooted in three semantic features: stativity, duration, and telicity (Novakov, 2009; Lundquist, 2012).

Stativity refers to a verb that is a state of being rather than an action (Binnick, 1991). For example, verbs used as emotion (want, love, thought) are stative verbs rather than action verbs. One way in which stative verbs are different from action verbs is that they remain unchanged for their entire duration in comparison to dynamic verbs, which express change over the course of the process (Binnick, 1991). In the example of the verb want, the wanting does not change while he subject wants whatever is expressed in the sentence. This is in comparison to the dynamic (action) verb running, which describes a process, typically with a beginning and endpoint, that changes throughout the process.

Duration refers to the relationship between the verb and the passage of time in the utterance (Petrović, 2016). A verb may be immediate and short-term, such as jump, or ongoing, such as running. Duration and state are frequently related. That is, a stative verb suggests a long or ongoing duration. Despite this relationship, state and duration are separate components in grammar and are identified separately from each other. For example, in the case of running, the duration may be short, such as in a 100-m dash, or long, such as in a marathon. In either case, there is a noted duration, which also suggests a fixed beginning and endpoint, even if the beginning and endpoint are not known in the utterance.

Telicity refers to the completeness of a verb (Lazović, 2008). If a verb is telic, it is complete (Verkuyl, 1972). For example, in simplest form, most past-tense verbs are telic. If the subject ran, it suggests the running is no longer taking place. Therefore, it is complete and telic. If a verb is atelic, it is not complete, which means it is currently occurring or is ongoing. For example, in simplest form, most present-tense verbs are atelic. If the subject is running, it suggests the running is in progress. Therefore, it is incomplete and atelic. Telicity is a significant component in determining perfectivity because of the need for the verb, event, or action to be complete in the perfective. 
Accomplishment. An accomplishment verb "describes a situation that is dynamic and durative, but has a necessary endpoint" (Sugaya \& Shirai, 2007, p. 3). That is, the event takes place over a period of time, but there is a known and natural end to that duration. For example:

(7) (a) Emily ran to her chair.

The endpoint is Emily's arrival at the chair. Since she ran to the chair, it can be concluded that, once she reached the chair, she was no longer running. This classification also suggests the events leading to the arrival at the chair. That is, if Emily ran to her chair, there was a state in which she was not yet at her chair or, for that matter, had not yet begun to run to her chair.

The accomplishment verb emphasizes the process or action, but includes the process leading to the accomplishment. This includes such verb phrases as climbed a mountain, walked to the park, or crossed the bridge. As in the case of (7) (a), the emphasis is on the process, but there is an inclusion of a clear and natural endpoint. Climbing a mountain is a process, but it is natural to conclude that when the climber reaches the top, the event exists in the past.

It should also be noted that, in the case of accomplishments, there is no indication of the length of duration (Mourelatos, 1978). In returning to (7) (a), if Emily ran to her chair over her lunch break, it may be that she only ran to the chair for five minutes of that lunch break, or it may have taken the entire lunch break. The length of duration is not the focus of the syntax in accomplishment verbs. Instead, the emphasis is frequently on the endpoint and what occurred to reach the endpoint.

Achievement. An achievement verb is one that is dynamic and immediate or punctual (Sugaya \& Shirai, 2007). The duration related to achievement may be implied or explicit, but there is a greater focus on the endpoint event rather than the process event. For example:

(7) (b) Emily found her chair.

An achievement is often used as climactic (Mourelatos, 1978). According to Mourelatos (1978), "[ [...T]hey can be dated, or they can be indefinitely placed within a temporal stretch, but they cannot in themselves occur over or throughout a temporal stretch" (p. 416). In (7) (b), for example, the emphasis is on the finding of the chair rather than the searching leading up to the achievement. However, unlike running to the chair, as in (7) (a), an achievement occurs immediately rather than over a period of time. An achievement is not a process or an ongoing event.

The achievement verb may be remembered based on its name. This verb classification is so named because the expression of an achievement in an individual's life would qualify as an accomplishment. This includes win a race, solve a puzzle, overtake an enemy, or publish a book. As in (7)(a), these verb examples focus on the endpoint, but the process leading to the endpoint is just as important as the endpoint because of its role in creating the endpoint event.

Activity. An activity verb is one that refers to a dynamic and durative situation, but does not have an inherent endpoint, though an endpoint may be suggested, implied, or stated as a clarification (Sugaya \& Shirai, 2007). It is expected that an activity verb requires time and has an endpoint, even if it is not explicitly expressed. For example:

(7) (c) Emily sat in her chair.

A significant difference between activities in comparison to achievements and accomplishments is in duration. While achievements and accomplishments either occur punctually or may occur either punctually or during a duration, there is the expectation that an activity verb requires time. In (7) (c), though there is no endpoint, it is understood that the event takes place over a period of time in order to be applicable. For example, if the sentence included the explanation that Emily sat in her chair during her lunch break, the activity classification requires that Emily was, is, and will be sitting in the chair for the entire duration of her lunch break (Mourelatos, 1978). An activity verb may be vaguer, but there is a clear beginning and end point to the activity. This includes such verb phrases as played chess or took a nap. There is no greater emphasis on the process than the endpoint or vice versa. Instead, the emphasis of these two components is more equal.

State. A state verb is one that is continuous unless impacted by some outside situation (Sugaya \& Shirai, 2007). Though it occurs over a period of time, it is unbounded (Passonneau, 1988). Unbounded means there is no designated or natural endpoint, as occurs with activities, achievements, and accomplishments. There is significantly less focus on the action in stative verbs. Instead, the focus is on the state of being or state of mind expressed in the stative verb. For example:

(7) (d) Emily wanted her chair.

Stative verbs differ from the previous three types in that they cannot typically be categorized as action verbs. According to Mourelatos (1978), "A state, as the name implies, involves no dynamics. Though it may arise, or be acquired, as a result of change, and though it may provide the potential of change, the state itself does not constitute a change" (p. 416). In (7) (d), "want" is a verb, but is not a tangible action in the same way as "sit" is in (7) (c). Additional stative verbs include emotion words, such as loved, feared, or respected, as well as states of being such as thought. It should also be noted that state verbs do not have progressive forms in English. As in (7) (d), it would not be proper English to say Emily is wanting her chair. Instead, English would use the past form - Emily wanted her chair or future form-Emily will be wanting her chair. Though future form may be difficult to use effectively.

\section{CONCLUSION}


The purpose of this research was to provide a foundation of information on tense and aspect on which to base an analysis of the perfective aspect in language. While tense is, simply, the time in which the expression occurred, aspect provides a viewpoint to provide greater context and understanding to the expression. The grammatical perspective of aspect is classified as either perfective, which refers to a complete action, or imperfective, which refers to an incomplete action. The lexical perspective of aspect is categorized in one of four classifications: accomplishment; achievement; activity; and state. Each of these four categorizations has unique characteristics in order to identify them in expressions. The verbs used in language can be applied to these four classifications to understand the intention of the expression more effectively.

\section{REFERENCES}

[1] Anderson, L. (1982a). The 'perfect' as a universal and as a language-particular category. In P. J. Hopper (Ed.) Tense-Aspect between Semantics \& Pragmatics, 227-64. Philadelphia, PA: John Benjamins Publishing Company.

[2] Bache, C. (1982). Aspect and aktionsart: Towards a semantic distinction. Journal of Linguistics, 18(1), 57-72. doi: $10.1017 /$ S0022226700007234.

[3] Bardovi-Harlig, K. (1992). The relationship of form and meaning: A cross-sectional study of tense and aspect in the interlanguage of learners of English as a second language. Applied Psycholinguistics, 13(3), 253-78. doi: $10.1017 /$ S0142716400005634.

[4] Bardovi-Harlig, K. (1998). Narrative structure and lexical aspect: Conspiring factors in second language acquisition of tenseaspect morphology. Studies in Second Language Acquisition, 20(4), 471-508.

[5] Bardovi-Harlig, K. \& Reynolds, D. W. (1995). The role of lexical aspect in the acquisition of tense and aspect. TESOL Quarterly, 29(1), 107-31. doi: 10.2307/3587807.

[6] Binnick, R. I. (1991). Time and the verb: A guide to tense and aspect. New York: Oxford University Press.

[7] Bybee, J. L. \& Dahl, Ö. (1989). The creation of tense and aspect systems in the languages of the world. Studies in Language, 13(1), 51-103.

[8] Carlota, S. Smith, (1997). The Parameter of Aspect, (Second Edition). Kluwer Academic Publishers, Dordrecht/Boston/London.

[9] DeLancey, S. (2001). The mirative and evidentiality. Journal of Pragmatics, 33, 369-382.

[10] Dowty, D. R. (1977). Toward a semantic analysis of verb aspect and the English 'imperfective' progressive. Linguistics and Philosophy, 1(1), 45-77. doi: 10.1007/BF00351936.

[11] Dowty, David. (1972). Studies in the Logic of Tense and Aspect in English. University of Texas dissertation.

[12] Dowty, David. (1982). Tenses, Time Adverbials and Compositional Semantic Theory. Linguistics and Philosophy. 23-24.

[13] Duan, M. (2013). A comparative study of perfect aspect category in English and Chinese. Theory and Practice in Language Studies, 3(2), 263-8. doi: 10.4304/tpls.3.2.263-268.

[14] Garey, H. B. (1957). Verbal aspect in French. Language, 33(2), 91-110.

[15] Gueron, J. and Lecarme J. (2008). Time and Modality. Springer Science, University of Paris, France. 3-21.

[16] Hamm, F. \& Bott, O. (2014). Tense and aspect. Stanford Encyclopedia of Philosophy. Retrieved from https://plato.stanford.edu/entries/tense-aspect/ . Jan, 23, 2019.

[17] Higginbotham James. (2009). Tense, Aspect, and Indexicality. Oxford University Press, London. 46.

[18] Jonathan, E. MacDonald. (1984). The Syntactic Nature of Inner Aspect, A Minimalist Perspective. John Benjamins Publishing Company, Amsterdam/Philadelphia. 20-40.

[19] Karen Zagnona. (2002). The syntax of Spanish. Cambridge University Press, UK. 17-33.

[20] Lazović, M. (2008). Imperfective aspect, aktionsart, telicity and boundedness. Bulletin Stiintific, seria A, Fascicula Filologie, 17(1), 43-50.

[21] Li, C. N., Thompson, S. A., \& McMillan Thompson, R. (1982). The discourse motivation for the perfect aspect: The Mandarin particle le. In P. J. Hopper (Ed.) Tense-Aspect between Semantics \& Pragmatics, 19-44. Philadelphia, PA: John Benjamins Publishing Company.

[22] Lundquist, B. (2012). Localizing cross-linguistic variation in tense systems: On telicity and stativity in Swedish and English. Nordic Journal of Linguistics, 35(1), 27-70. doi: 10.1017/S033258651200011X.

[23] Marantz, A. (1997). No escape from syntax: Don't try morphological analysis in the privacy of your own lexicon. University of Pennsylvania Working Papers in Linguistics, 4(2), 201-25.

[24] Mourelatos, A. P. D. (1978). Events, processes, and states. Linguistics and Philosophy, 2, 415-34.

[25] Novakov, P. (2009). Semantic features of verbs and types of present perfect in English. Selected Papers from the $18^{\text {th }}$ ISTAL, 281-8. Retrieved from http://www.enl.auth.gr/symposium18/papers/29_Novakov.pdf . Feb, 02, 2019.

[26] Pancheva, R. (2003). The aspectual makeup of perfect participles and the interpretations of the perfect. Retrieved from http://www-bcf.usc.edu/ pancheva/Pancheva(2003).pdf . Mar, 06, 2019.

[27] Passonneau, R. J. (1988). A computational model of the semantics of tense and aspect. Computational Linguistics, 14(2), 44-60.

[28] Petrović, B. (2016). English phrasal verbs with the particles down, off and up and progressive aspect, 265-78. Retrieved from http://scindeks-clanci.ceon.rs/data/pdf/2466-3905/2016/2466-39051607265P.pdf . Feb, 04, 2019.

[29] Pustejovsky, J. (1991). The generative lexicon. Computational Linguistics, 17(4), 409-41.

[30] Robinson, R. E. (1990). The primacy of aspect: Aspectual marketing in English interlanguage. Studies in Second Language Acquisition, 12(3), 315-30. doi: 10.1017/S0272263100009190.

[31] Shirai, Y. (1998). Where the progressive and resultative meet imperfective aspect in Japanese, Chinese, Korean, and English. Studies in Language, 22(3), 661-92. doi: 10.1075/s1.22.3.06shi.

[32] Singh, M. (1998). On the semantics of the perfective aspect. Natural Language Semantics, 6, 171-99.

[33] Smith C. S. (1997). The parameter of aspect $\left(2^{\text {nd }}\right.$ ed.). Boston, MA: Kluwer Academic Publishers. 
[34] Soh, H. L. \& Gao, M. (2006). Perfective aspect and transition in Mandarin Chinese: An analysis of double -le sentences. In P. Denis et al. Proceedings of the 2004 Texas Linguistics Society Conference, 107-22. Somerville, MA: Cascadilla Proceedings Project.

[35] Sugaya, N. \& Shirai, Y. (2007). The acquisition of progressive and resultative meanings of the imperfective aspect marker by L2 learners of Japanese: Transfer, universals, or multiple factors? SSLA, 29, 1-38. doi: 10.1017/S0272263107070015.

[36] Verkuyl, H. (1972). On the compositional nature of aspects. Dordrecht: Reidel.

[37] Zeno Vendler, (1957). Verbs and Times. The Philosophical Review, Vol. 66, No. 2. Cornell University.147-149.

Kamal Kahzal Kamal, he is assistant instructor at Imam AL- Kadhum College (IKC) at the Department of The English Language, Iraq, Maysan. He is a linguist researched scholar, published articles on: "Syntactic Perfective Aspect", "Kinship Semantics; English \& Arabic Language", "Syntactic of English middle constructions". 